\title{
Learning in Government Agencies: The Bureau of Land Management National Training Center
}

\author{
By Marlo Draper and Philip Cooley
}

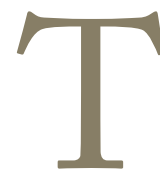

he Bureau of Land Management (BLM) manages about 245 million acres of public lands for multiple uses throughout the western United States and Alaska. Of this total acreage, the BLM administers livestock grazing on about 157 million acres. To manage and administer the rangeland management program, the BLM employs specialists that have some combination of technical and/ or administrative responsibilities. Depending on their functions and duties, some positions are classified in a professional series and require a degree in rangeland management or a closely related field, whereas other positions do not have an education requirement. Regardless of a position's educational requirement, all BLM employees involved in the rangeland management program benefit from additional or specialized training. The BLM's National Training Center (NTC) located in Phoenix, Arizona provides this benefit. The NTC does not duplicate training that can be obtained at a college or university. Instead the NTC supplements what is taught at the university by providing training that is tailored to meet BLM's need to have employees that are versed in BLM's roles, responsibilities, procedures, and authorities so that they are fully capable of implementing a successful rangeland management program in concert with multiple other uses on the BLM's vast western holdings.

\section{Bureau of Land Management and the National Training Center}

The BLM was created as an agency in the Department of the Interior in 1946 by combining the General Land Office with the Grazing Service. With its inception, one of the primary functions of the BLM was to administer the provisions of the Taylor Grazing Act of 1934 (TGA) with the expectation that the lands would eventually be disposed. Over time, new legislation, such as the Federal Land Policy and Management Act of 1976 (FLPMA), National Environmental Policy Act of 1969 (NEPA), and the Endangered Species Act of 1973 (ESA) have changed the mission of the BLM from an agency that administered grazing in a custodial manner to an agency that actively manages federally controlled rangelands for sustainability and multiple use. There have not been any major changes or new legislation (such as TGA, FLPMA, NEPA, etc.) that impacts the management of public lands in many years. However, that does not imply that the need for continuing education of the BLM staff that administers these public lands has diminished. In fact, the need is just as high, if not higher, to continually educate the BLM employees responsible for managing public lands throughout the western United States. The NTC serves this critical role in providing training to ensure that new and existing employees stay abreast with new information, concepts, and management techniques so that they can better understand how to do their jobs and efficiently perform their functions and duties. The primary focus of training offered through the NTC is focused internally for BLM employees; however, there are some training opportunities that are available to employees of other agencies, as well as private individuals.

Just as the mission and regulatory requirements of the BLM have changed over the years, the need for continuing education or training also has changed for the BLM. The BLM began an internal training program in 1969 with the creation of the Lands and Minerals Training School that offered a 6-week course to new lands and mineral specialists. This training was needed because there was no formal training available for realty specialists or private sector training available to prepare BLM mineral specialists to perform the required work. Following the success of this training program, a long-term training program (range school) dedicated to Rangeland Management Specialists (RMS) was created. The range school was a multiweek, all-inclusive program that covered BLM specific requirements to become a fully proficient RMS. This included such topics as laws and policies that are not part of a college/university range curriculum, as well as basic principles of rangeland management that are part of a college/university range curriculum. The range school was a very successful program throughout the 1980s and into the early 1990s; however, attendance in the range school started to drop in the 1990s. The main factor behind this drop in attendance was a perception by supervisors 
that they could not have new employees gone from their duty station for a block of 4-6 weeks to attend training. This concern by management, coupled with a reduction in budgets and travel, forced the NTC change from an all-inclusive training program for employees working in the rangeland management program. Today, NTC focuses internal training opportunities in areas that are not covered in a 4-year degree program. Each of these training programs is no longer than 1 week, allowing BLM RMSs the opportunity to attend a variety of trainings that can be spaced out over time. The NTC also looks to colleges/universities and other agencies for training opportunities that apply to rangeland management as a whole and not specific to BLM. Instead, NTC focuses on offering training opportunities that are not available through other venues and utilizes a variety of delivery techniques to reach as wide an audience as possible.

\section{Rangeland Management Specialists}

Currently there are more than 400 Rangeland Management Specialists within the BLM. Each of these RMSs had to meet the Office of Personnel Management's classification requirement for the RMS General Series 454, which demonstrates an individual has a foundation in terms of rangeland theories, principles, and concepts. This foundation is a required first step in order for a professional to become a competent RMS for the BLM.

In addition to the theories, principles, and concepts of rangeland management, BLM RMSs must ensure all actions on BLM-administered lands are in compliance with federal laws that have been administratively interpreted through regulations and internal policy, including agency manuals, handbooks, and memoranda. Although a college/university student might obtain an overview of federal laws (such as the NEPA, FLPMA, and TGA), the application of these laws by federal rangeland professionals is not part of college/university rangeland-related curricula. To bridge the knowledge gap between what is learned at a college/university and what is required to become a fully qualified RMS, the BLM NTC provides various training opportunities for both new and current employees based on the competencies required to complete specific tasks.

\section{Competency-Based Training}

Ensuring that employees receive the training that is of the greatest value to them and to the BLM requires a clear understanding of and focus on competency-based education to increase and enhance essential knowledge, skills, and behaviors. RMS competencies are based upon specific tasks that can be divided into two primary categories: 1 ) grazing administration to comply with the United States Code of Federal Regulations (43 CFR 4100), and 2) managing renewable rangeland resources to meet the agency's multiple-use mission. NTC has and continues to provide training that focuses on specific job duties that BLM employees need to perform. Prior to the current competency-based training approach, NTC training courses were all encompassing, and covered all required knowledge, skills, and abilities for an RMS in one long session. Under this new competency-based approach, classes are developed for each specific job competency, resulting in an increase in the number of classes, but shorter course lengths.

\section{What NTC Offers}

There are several agencies within the Department of the Interior responsible for the management of rangelands. However, BLM is the only agency that manages rangelands for sustainable forage production and consumption by domestic livestock, while also managing these resources for multiple uses. Although managing for domestic livestock production while allowing for a wide variety of other uses is not unique, it does require a wide array of training to ensure BLM RMSs are aware of the most recent information in both rangeland management and internal BLM policies. The NTC separates training opportunities for RMSs into two main categories: 1) competencies required for sound range management, and 2) competencies specific to BLM requirements.

The foundation for rangeland resources competencies in assessing, inventorying, planning, and monitoring comes from formal college/university curricula. Because these tasks are universal to all range professionals, not just BLM, we rely on training opportunities such as workshops provided by county extension or the Society for Range Management and, when available, training events offered by universities and other agencies, to ensure BLM RMSs have the skills to perform these tasks. In some cases, NTC creates and/or sponsors training opportunities in various aspects of rangeland management that would apply to rangeland management "as a whole" and not specific to BLM. Because these courses are not specific to BLM, these training opportunities are available not only to BLM employees but other state and federal employees as well as private citizens. Examples of these training courses include:

- Interpreting and Measuring Indicators for Rangeland Health: an interagency, qualitative technique that uses some quantitative measures to help BLM RMSs evaluate the status of Standards for Rangeland Health.

- Riparian, Proper Functioning Condition Lotic and Lentic Systems: an interagency, qualitative technique that is designed to help BLM RMSs evaluate the status of both lentic and lotic riparian systems.

There are job tasks specific to BLM range professionals. To ensure employees can complete these tasks, NTC offers a variety of training opportunities that are typically not available to other state and federal employees or private citizens. Examples of these training courses include:

- Grazing Administration: prepares range professionals to apply current laws, policies, and regulations; issue grazing authorizations and grazing bills; process applications for transfer; conduct compliance inspections; and authorize construction of range improvement projects. 
- Rangeland Administration System (RAS): prepares range professionals to use the automated computer system to complete the various grazing administration tasks.

- Decisions, Appeals, and Hearings: prepares range professionals for legal proceedings.

\section{RMS Learning Plan}

Similar to the college/university course catalog developed for specific degree programs, NTC provides range professionals with a learning plan that shows what training opportunities are available and recommendations for when to take advantage of training opportunities for maximum benefit to both the learner and the agency.

The RMS learning plan is divided into six major categories (Table 1):

- First 6 months of employment,

- Six months to 1 year of employment,

- Years 1 through 3 of employment,

- Years 4 through 5 of employment,

- Mid-career, and

- Optional training.

The training specified for the first 6 months of employment is geared to the specific office and includes a mix of formal and informal training. When starting a new job, the first phase of training is primarily conducted informally by a supervisor or coworker who has been in the office for a while and is familiar with all the specific office polices. There also might be job-specific requirements that require certifications through a more formal training during this time period.

After the "Office Orientation" is completed, BLM employees start taking formal training courses on key aspects of the job they will be performing. These training courses are typically geared to help BLM employees complete tasks that are a major portion of their duties. Throughout the first year of employment, the training is primarily focused on learning the basic skills required to complete daily tasks. The next phase of training involves building on these basic concepts and becoming more competent in completing more complex tasks. These training courses typically are needed between Year 1 and Year 5 of employment. In order to prioritize and try to accommodate training needs, these courses are divided into two categories in the learning plan.

As a BLM range professional approaches mid-career, there are typically two career paths. For those folks who wish to continue working in range management at the field level, this is when refresher training is encouraged. In some cases, people might prefer to pursue a career change, such as a management/supervisory role, and additional training could be required to prepare for these new opportunities.

Finally, the remaining training in the RMS Learning Plan is considered "optional." These training opportunities range from task-specific trainings to individual improvement.

\section{Training Delivery Methods}

Traditionally NTC training was delivered in a classroom setting. However, time limitations resulted in changes to how trainings are delivered. Traditional classroom training has not been able to keep up with demands due to limits on class size. In other cases, a trainee's inability to travel due to a variety of reasons, means that only those who can travel have opportunities to receive training. Classroom training is not always cost-effective, especially for an agency such as BLM, where employees reside around the United States. Also, as technology changes, the learning preferences for newer employees are moving away from traditional classroom instruction.

BLM continues to look for efficient and effective business and management processes to improve how we deliver training. Using various distance-learning techniques provides multiple training opportunities for all employees. Employees can report to work and attend training at their duty station, reducing the number days they are away from the office. Scheduling a time to take on-line training is easier. With fewer days traveling, employees reduce the amount of time they are away from their families. Because transportation, subsistence, and lodging are not being used, training becomes more cost-effective.

NTC uses both live and prerecorded platforms to provide instructional material to learners off-site. These platforms include: webinar, video broadcast (satellite TV), video conferencing, and audio forms (conference calls, podcast, etc.). NTC makes every effort to record all of the live training events and posts these events for employees and others to view at a later time. Although these new learning platforms are becoming more common, NTC is not abandoning traditional classroom training. Blending both classroom and live/prerecorded sessions provides a flexible learning environment, and shorter classroom settings are devoted primarily to assessing the mastery of the subject matter and giving hands-on experience.

Similar to colleges/universities, BLM maintains a training transcript for all official training. These transcripts are important to track completion of mandatory training and show how employees qualify for other positions when career planning.

NTC has an information library available through the internet called the Knowledge Resource Center (KRC). The KRC provides access to on-line training, documents, satellite events, and best management practices (such as case studies, reference materials, and video presentations). One of the main purposes for the $\mathrm{KRC}$ is to provide access to official NTC training without an employee having to attend the actual training session (refreshers, etc.). The KRC is accessible anytime, so when employees need to accomplish a task quickly, critical information is available at their fingertips. The KRC uses a search engine and menu bars for finding resources in a particular subject area, program, or competency. Requirements for accessing KRC resources include Adobe Reader and Flash.

\section{Conclusion}

Range managers are aware of the importance of monitoring in all aspects of range management. These monitoring pro- 


\section{Table 1. Example training opportunities over a Bureau of Land Management (BLM) Rangeland Manage-}

ment Specialist's (RMS's) career from the RMS Learning Plan

\section{RMS Learning Plan}

\begin{tabular}{|c|c|c|}
\hline \multirow[t]{7}{*}{ First 6 months } & \multirow[t]{4}{*}{ Informal training } & Payroll \\
\hline & & Travel \\
\hline & & File management \\
\hline & & etc. \\
\hline & \multirow[t]{3}{*}{ Formal training } & All-terrain vehicles \\
\hline & & First aid \\
\hline & & etc. \\
\hline \multirow[t]{3}{*}{ Second 6 months } & \multicolumn{2}{|c|}{ Rangeland Administration System (RAS) (computer) } \\
\hline & \multicolumn{2}{|c|}{ National Environmental Policy Act (NEPA) } \\
\hline & \multicolumn{2}{|c|}{ Interpreting indicators for rangeland health } \\
\hline \multirow[t]{2}{*}{ Years $1-3$} & \multicolumn{2}{|c|}{ Grazing administration } \\
\hline & \multicolumn{2}{|c|}{ Riparian monitoring/proper functioning condition } \\
\hline \multirow[t]{2}{*}{ Years 4-5 } & \multicolumn{2}{|c|}{ Decisions, appeals, and hearings } \\
\hline & \multicolumn{2}{|l|}{ NEPA } \\
\hline \multirow[t]{2}{*}{ Mid-career } & \multicolumn{2}{|c|}{ Grazing administration } \\
\hline & \multicolumn{2}{|l|}{ Emerging leaders } \\
\hline \multirow[t]{6}{*}{ Optional } & \multicolumn{2}{|l|}{ Map reading } \\
\hline & \multicolumn{2}{|l|}{ Fire } \\
\hline & \multicolumn{2}{|c|}{ Pesticide applicators } \\
\hline & \multicolumn{2}{|c|}{ Sagebrush restoration } \\
\hline & \multicolumn{2}{|l|}{ Public speaking } \\
\hline & \multicolumn{2}{|l|}{ SRM } \\
\hline
\end{tabular}

grams ensure that whatever management practices are being used have the appropriate outcome and the rangelands are responding as anticipated. The NTC utilizes a similar approach to ensure the BLM's training program continually offers the best and most recent information. Periodically, NTC conducts a needs assessment to determine what/if any changes are needed in training opportunities to provide BLM with the most knowledgeable and competent employees possible. In addition, NTC conducts course assessments to determine if its courses are meeting the needs of the student, supervisor, and BLM.

For more training resource information, $\mathrm{KRC}$ can be accessed at: http://www.blm.gov/ntc/st/en.html; and sched- uled training courses can be found at: http://www.doi.gov/ doilearn/index.cfm. For more information on the Bureau of Land Management, go to http://www.blm.gov. The BLM's National Training Center is located at 9828 N. 31st. Ave., Phoenix, AZ 85051, USA.

Authors are Branch Chief, Resources and Planning, BLMNTC, Phoenix, AZ 85051, USA (Draper); and Training Coordinator (Range, Grazing, and Wildhorse and Burro), BLM-NTC, Phoenix, AZ 85051, USA, pcooley@blm.gov (Cooley). 